\title{
Top-up search and the attentional blink: A two-stage account of the preview effect in search
}

\author{
Melina A. Kunar \\ Visual Attention Laboratory, Cambridge, MA, USA \\ Kimron L. Shapiro \\ School of Psychology, University of Wales, Bangor, UK \\ Glyn W. Humphreys \\ Behavioural Brain Sciences Centre, University of Birmingham, \\ Birmingham, UK
}

\begin{abstract}
An inefficient visual search task can be facilitated if half the distractor items are presented as a preview prior to the presentation of the remaining distractor items and target. This benefit in search is termed the preview effect. Recent research has found that a preview effect can still occur if the previewed items disappear before reappearing again just before the search items (the "top-up" procedure). In this paper we investigate the attentional demands of processing during the preview and the top-up periods. Experiment 1 found that if attention is withdrawn from the topup stage then no preview effect occurs. Likewise if attention is withdrawn from the initial preview period then the preview effect is reduced (Experiment 2). The data suggest that the preview effect is dependent on attention being paid both to the initial display and also to the re-presentation of the old display before the search display appears. The data counter accounts of preview search in terms of automatic attention capture by new items or by inhibition of return. We discuss alternative accounts of the results, and in particular suggest an amalgamation of a temporal grouping and a visual marking account of preview search.
\end{abstract}

In order to successfully navigate through the world the visual system has to select relevant objects over irrelevant ones. One such mechanism of selection was suggested by Watson and Humphreys (1997) who found that new items

Please address all correspondence to Melina A. Kunar, Visual Attention Lab, 64 Sidney Street, Cambridge, MA 02139, USA. E-mail: kunar@search.bwh.harvard.edu

This work was supported by an ESRC grant to MAK, a Wellcome project grant (071944) to KLS, and an MRC grant to GWH. The authors would like to thank Kyle Cave and two anonymous reviewers for their comments. 
could be selectively attended over old in visual search, when display items were separated over time (a preview of distractors followed by the new search items). This is the "preview effect" in search.

In their experiments, Watson and Humphreys (1997) segregated a colourform conjunction task over time, with half the distractor items from one set appearing $1 \mathrm{~s}$ before the other distractors and target item (the search set). The old distractors then remained in the field when the search set appeared. Stimuli in the preview set shared their shape with the target item, whereas items in the search set shared their colour. When both the preview set and the search set were presented simultaneously search for the target item was inefficient, with search slope functions (reaction times, RTs, across display size) typically in the range of $25-30 \mathrm{~ms}$ per item. However, when the preview display was presented prior to the search set, search became more efficient with search slopes resembling conditions where the search set was presented alone. To account for this, Watson and Humphreys suggested that old, previewed items were inhibited or "visually marked", a process that required active engagement of attention on the part of observers.

Several experiments using dual-task procedures have confirmed the need for attention in generating the preview effect. Watson and Humphreys (1997) found that when attention was engaged, by a secondary visual task during the preview period, search once again became inefficient (see also Olivers \& Humphreys, 2002). Humphreys, Watson, and Jolicoeur (2002) compared performance with auditory and visual secondary tasks during the preview period. When either task began concurrently with the onset of the preview (with the preview plus the secondary task then continuing for a second before the onset of the search display), search was disrupted. However, if the secondary task was presented after the onset of the preview stimuli, then only the visual task disrupted search. Apparently, if there was sufficient time to code the preview, then attention could be engaged on an auditory task without further disruption. Nevertheless, the auditory task could affect search if it prevented the preview from being encoded in the first place. In contrast to this, the visual secondary task was disruptive even after the preview had been encoded. These data suggest that the preview period can be fractionated into two components: (a) An initial period needed to encode the preview, and (b) a secondary stage in which a representation of the old items is maintained. Humphreys et al. proposed that the initial period requires centrally driven attentional resources, whereas the secondary stage is solely dependent on modality specific attentional resources.

Although Watson and Humphreys (1997) suggested that the preview effect occurred due to inhibitory filtering, two other accounts have been proposed. Firstly, Jiang, Chun, and Marks (2002; see also Jiang \& Wang, 2004) proposed a temporal grouping account. They argued that the separate onsets of the preview and the search sets meant that they could be segmented 
into two temporal groups, each of which could be attended selectively. When the second search display is selectively attended, the preview effect is generated. Secondly, Donk and Theeuwes $(2001,2003)$ proposed that the preview effect is due solely to onset capture by the search set. Here attention would automatically be directed to the new items and away from the old.

Recently Kunar, Humphreys, and Smith (2003) showed that a preview effect could be found if the preview period was segregated into two different time periods. In this "top-up" condition the preview initially appeared for at least $450 \mathrm{~ms}$ before disappearing for $250 \mathrm{~ms}$, and then reappearing $150 \mathrm{~ms}$ before the search display. Kunar, Humphreys, and Smith found that search in this condition was efficient and comparable to a "standard" preview condition where the preview distractors were presented for $700 \mathrm{~ms}$ and followed immediately by the search set. If, however, the preview set was only presented for $150 \mathrm{~ms}$ prior to the search set, then no preview effect was observed, and search to find the target item became comparably inefficient (see also Humphreys et al., 2004, for similar evidence on the time course of preview search). It seems that in order to produce an efficient preview effect, the initial presentation of the old items is important. Furthermore, if the preview distractors initially appear, disappear, and then reappear simultaneously with the onset of the new items, then the preview effect is abolished (Kunar, Humphreys, Smith, \& Watson, 2003; Watson \& Humphreys, 1997). Thus, in order to produce efficient search in the top-up procedure, the representation of the preview shortly before the onset of the search items is important. Kunar, Humphreys, and Smith (2003) suggested that the brief representation of the preview, before the search display, "topped up" the earlier representation of the preview, helping it to remain deprioritized in search. This "top-up" display also prevented the preview regrouping with the search set on the basis of their common onsets, when the old and new items appear together. This suggests that temporal grouping, based on common onsets, can also play a role in preview search.

The occurrence of the top-up effect is somewhat problematic for a pure temporal segmentation account of preview search. This is because neither the initial preview (once offset) nor the initial (short) top-up display is sufficient to generate efficient segmentation, so the time intervals, defining the displays alone, are not responsible for the top-up effect. The same arguments apply to an onset capture account of preview search (Donk \& Theeuwes, 2001, 2003). In the top-up procedure, the onset of the new items is insufficient to produce efficient search when the preview is short (top-up alone), and there seems little reason why the earlier onset of the preview display, around $1 \mathrm{~s}$ before the search set, should influence responses to the onsets from the new search items. 
Despite this, Donk and Verburg (2004) have recently argued that attentional capture could account for the preview effect if the previewed items (in the top-up experiment) had undergone inhibition of return (IOR). They suggest that with just a short $150 \mathrm{~ms}$ preview, the onset of the preview items may have masked the onset of the new, leading to inefficient search. However, in the top-up condition, if the preview items had undergone IOR their re-onset would not attract attention, allowing efficient search of the new items. In this case, any masking effect of the re-onset of the previewed items would be removed. Accordingly, then if this account were to hold true, (further) removing attention to the preview items, when they re-onset, should still produce a preview effect.

In this paper, we remove attention to both the early and the latter stages of the preview period in order to investigate the role of inhibitory filtering, temporal grouping, and attentional capture in the preview effect. In particular, we question whether IOR is responsible for the top-up preview effect (as proposed by Donk \& Verburg, 2004). Here we use a dual-task paradigm to probe the role of attention in the top-up procedure. Similar to Olivers and Humphreys (2002), the dual-task paradigm combined preview search with an attentional blink task. The attentional blink (AB) occurs when attention is used to process a primary target (T1) leaving subsequent target detection impaired if a secondary target (T2) falls within 100-500 ms of T1 (Raymond, Shapiro, \& Arnell, 1992; see also Shapiro, Arnell, \& Raymond, 1997, for a review). Olivers and Humphreys found that, if a preview was presented during an $\mathrm{AB}$ (i.e., shortly after $\mathrm{T} 1$ ), then the usual search benefit was reduced. In the present study we used the top-up procedure to probe when attention might be demanded under preview search conditions, utilizing the fact that the top-up procedure separates out processes that might be involved in encoding the preview when it is first presented, from processes involved in using the top-up to help ignore old items in search. There are two experiments. Both experiments used a top-up procedure in which a preview appeared initially (for at least $450 \mathrm{~ms}$ ) and was followed by a blank interval of $250 \mathrm{~ms}$, before the top-up display appeared for $150 \mathrm{~ms}$. After the top-up display, the new search items appeared. In the crucial condition of Experiment 1, the top-up display fell within the AB. If attention to this re-presented preview is necessary in order to ignore it in subsequent search, then the preview benefit should be reduced. In Experiment 2, the role of attention to the initial preview was tested, by presenting the first preview during an $\mathrm{AB}$. If it is important to attend to and encode the initial display to generate a preview benefit, then the $A B$ should disrupt the preview benefit.

The predictions made by other accounts of preview search differ from this. Let us examine what we expect to happen if IOR is responsible for the benefit found in the top-up preview effect. In Experiment 1 the top-up 
appears during an $\mathrm{AB}$. Under these circumstances, the initial preview should still be searched and IOR applied. Top-up items, falling at the same locations as the original previews should be ignored again. Indeed, it is possible that search might even benefit from the top-up display appearing during an $A B$, if it is then even less likely that the re-presented old items capture attention. The experiment also tested a further idea derived from the argument that preview search reflects automatic temporal segmentation of old and new displays (Jiang et al., 2002). If there is automatic temporal segmentation, the top-up may serve as a passive cue to aid this process, generating a preview benefit under top-up conditions (Kunar et al., 2003). For this account, presenting the top-up during an $\mathrm{AB}$ would have little impact. These different possibilities were tested here.

\section{EXPERIMENT 1}

Experiment 1 investigated what happens when attention is removed from the top-up stage of top-up preview search. In order for a preview effect to occur, Kunar et al. (2003) found that following the offset of a preview, the old items need to be re-presented for $150 \mathrm{~ms}$ before the onset of new items (the top-up period). We examine whether this latter top-up stage requires attention to be discounted from search or whether it is actually ignored in any case, on the basis of IOR applied to the earlier preview.

\section{Method}

Participants. Twelve participants ( 3 male and 9 female) took part for the attainment of course credits. Their ages ranged from 19 to 52 (mean age 23.9 years) and they were all taken from a population of undergraduates at the University of Wales, Bangor. All participants had normal or corrected-tonormal eyesight.

Stimuli. The experiment was conducted on a Pentium III computer with a $33 \mathrm{~cm}$ SVGA monitor (16-bit colour, $1024 \times 768$ resolution, $100 \mathrm{~Hz}$ refresh) running E-Prime 1.1 experimental software. The stimuli were presented on a uniform black field at an average viewing distance of 60 $\mathrm{cm}$. Alphanumeric stimuli were presented in white 12-point Times New Roman font (except the mask items which were presented in 18-point font). Both the target and the mask items were presented in the centre of the screen. Each visual search item subtended a visual angle of $0.95^{\circ} \times 0.76^{\circ}$.

The visual search task involved finding a blue $\mathrm{H}$ amongst distractor items of green Hs and blue As. On each trial participants had to decide whether the bar of the blue $\mathrm{H}$ was higher or lower than the mid-point of the y-axis for the shape. The surrounding green $\mathrm{H}$ distractors also randomly had bars in a 
position above the vertical mid-point or below it, in order to preserve conjunction conditions, by making the distractor $\mathrm{Hs}$ similar to the target $\mathrm{H}$. The target was present on every trial. Similar stimuli have been used by Kunar at al. (2003), who demonstrated a standard preview benefit.

In the conjunction and each preview condition, there were 4,8 , or 16 items in total in the search displays. The conjunction baseline provides a measure of search efficiency if all the items compete for selection in the final displays in the preview conditions. If the old items cannot be ignored, then the slope of the serial functions for the preview conditions should match that found in the conjunction baseline.

For the attentional blink task we used a "skeletal" rapid serial visual presentation (RSVP) stream, where only the targets and their masks were presented (see Ward, Duncan, \& Shapiro, 1997). By using only the critical items of an RSVP stream we cut down the time taken to elicit an AB. This was important, as in these conditions, the RSVP stream had to fit within the time constraints of the top-up preview. Previous work has shown that if the timings within this condition change (especially if the offset period is increased, see Kunar \& Humphreys, in press) then the preview effect is disrupted. In the present case the attentional blink task involved participants responding to the identity of a white letter that was presented prior to the visual search display. Participants were informed that the letter would come from the top row of the keyboard (i.e., Q, W, E, R, T, Y, U, P; I and O were not presented given their resemblance to digits). All letters were presented in uppercase and appeared at random. Each letter was masked by either a "£" sign or a "\$" sign. Pilot data showed that detection of a secondary target (T2) was impaired for up to $355 \mathrm{~ms}$ after T1 had been presented, using these stimuli. After $446 \mathrm{~ms} \mathrm{T2}$ detection reached the efficiency of a single target baseline where only T2 had to be attended (i.e., T1 was ignored).

Design and procedure. Each participant was tested in four conditions: (a) A conjunction baseline; (b) a "standard" top-up preview condition; (c) a top-up preview condition with the $150 \mathrm{~ms}$ repreview in the blink; and (d) a top-up preview condition with the $150 \mathrm{~ms}$ repreview outside of the blink. Each search condition was presented in a separate block. The experimental blocks each contained 90 trials ( 30 per display size). The order of the blocks were randomized and participants were given a practice session before each condition. The experiment lasted approximately $50 \mathrm{~min}$ in total.

In the conjunction condition, green $\mathrm{Hs}$, blue As, and a blue $\mathrm{H}$ were presented simultaneously. In the "standard" top-up preview condition, green Hs appeared for $740 \mathrm{~ms}$, disappeared for $250 \mathrm{~ms}$, and then reappeared 150 ms prior to the onset of the blue As and the blue H. The top-up preview in the blink was similar to this except that $600 \mathrm{~ms}$ after the green $\mathrm{Hs}$ were presented a white letter (T1) appeared at fixation for $24 \mathrm{~ms}$. After an 
interstimulus interval (ISI) of $41 \mathrm{~ms}$ this was followed by a mask (either a $£$ or a \$) that was presented for $74 \mathrm{~ms}$. During these presentations the green Hs were always visible so that the total initial preview period equalled approximately $740 \mathrm{~ms}$. The green $\mathrm{Hs}$ then offset for $250 \mathrm{~ms}$ and reappeared for $150 \mathrm{~ms}$ before the blue As and blue $\mathrm{H}$ were added. In this condition both the offset period and the $150 \mathrm{~ms}$ re-presentation fell inside the generated attentional blink. The top-up preview outside the blink condition was identical to this except $\mathrm{T} 1$ and its mask were presented after only $450 \mathrm{~ms}$ (i.e., covering more of the preview period, but further from the appearance of the top-up). After the mask had disappeared the green $\mathrm{Hs}$ were presented for a further $150 \mathrm{~ms}$ before the offset period, so that again the total initial preview period equalled $740 \mathrm{~ms}$. In this case the generated attentional blink should have dissipated by the time that the old items re-onset.

In each condition a fixation dot appeared in the centre of the screen for $550 \mathrm{~ms}$ followed by either the preview or the full search display (in the conjunction baseline). Participants were asked to keep their eyes on the fixation dot until the second set of stimuli were presented and then respond to the blue $\mathrm{H}$ by pressing either an "a" or a " $\mathrm{z}$ " for a high or a low bar respectively, as quickly but as accurately as they can. After their response, participants were then asked to identify the initial white letter (if shown) by pressing its corresponding key. Example displays for each condition can be seen in Figure 1.

\section{Results}

Participants correctly reported $\mathrm{T} 1$ on $95 \%$ of the trials. Table 1 shows the percentage of $\mathrm{T} 1$ errors for each condition across display size. Although there was a small, but reliable, decrease in errors over display size, $F(2,20)=5.7, p<.05$, there was no effect of T1 accuracy across condition, $F(1,10)=0.1, p=n s$, nor a reliable Condition $\times$ Display size interaction, $F(2,20)=0.4, p=n s$. Trials where T1 was not correctly identified were discarded from further analysis. Figure 2 shows the mean correct RTs as a function of display size for Experiment 1. The error rates are given in Table 2, and Table 3 shows the descriptive statistics.

\section{$R T S$}

One subject was dropped due to high error rates (over 30\%). A two-way within-subjects analysis of variance (ANOVA), with condition and display size as its main factors, was used to compare the RTs for all conditions. There was a reliable main effect of condition, $F(3,30)=3.58$, $p<.05$ and of display size, $F(2,20)=72.12, p<.01$. The Condition $\times$ 
Conjunction

$$
\begin{array}{ll}
\mathrm{H} \\
\hdashline \\
\hdashline
\end{array}
$$

Standard top-up preview

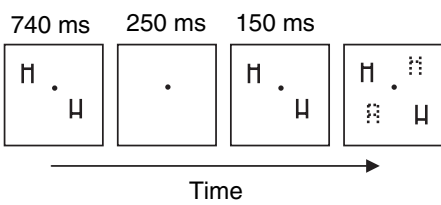

Top-up preview inside the blink

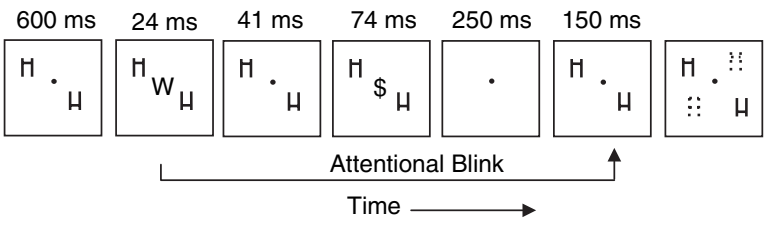

Top-up preview outside the blink

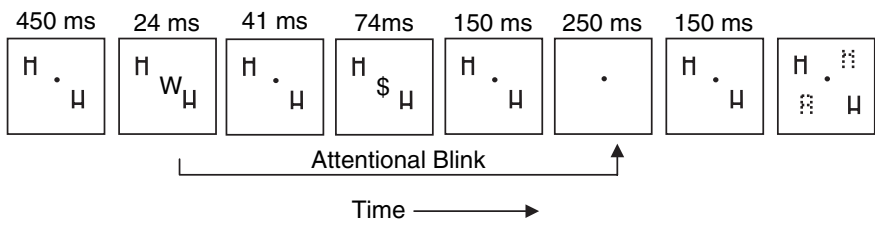

Figure 1. Example displays of each condition in Experiment 1. Solid lines represent green items, whereas dotted lines represent blue stimuli. Due to figure size constraints we only present four items in each display. In the experiment proper the displays contain 4,8 , or 16 items, which appear at random locations within the display. Please note that the scale of each item is not to size.

TABLE 1

Percentage of errors for T1 responses in Experiments 1 and 2

\begin{tabular}{lccc}
\hline & 4 & 8 & 16 \\
\hline Experiment 1 & & & \\
$\quad$ Top-up preview in the blink & 5.8 & 6.7 & 3.9 \\
Top-up preview not in the blink & 6.7 & 5.5 & 3.3 \\
Experiment 2 & & & \\
$\quad$ Conjunction & 7.5 & 6.4 & 10.6 \\
450 ms initial preview in the blink & 7.2 & 9.2 & 9.7 \\
450 ms initial preview with no blink & 6.1 & 6.7 & 7.8 \\
\hline
\end{tabular}




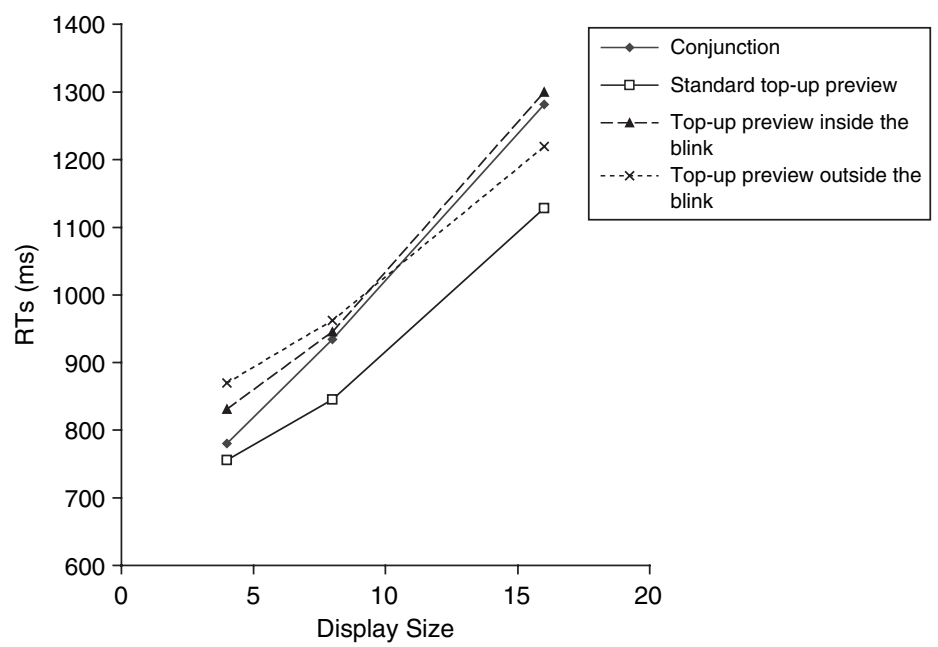

Figure 2. Mean correct RTs (ms) for each condition in Experiment 1.

Display size interaction also reached significance, $F(6,60)=3.60, p<.01$. The ANOVA was then broken down so that individual comparisons between conditions could be made.

Conjunction vs. the standard top-up preview. There was a reliable main effect of condition, $F(1,10)=5.24, p<.05$ and of display size, $F(2,20)=$ $58.90, p<.01$. The Condition $\times$ Display size interaction also reached significance, $F(2,20)=3.68, p<.05$. There was a greater increase in RTs with display size in the conjunction condition than in the top-up preview. This replicates Kunar et al. (2003).

TABLE 2

Percentage of errors for all search conditions in Experiments 1 and 2

\begin{tabular}{llll}
\hline & 4 & 8 & 16 \\
\hline Experiment 1 & & & \\
$\quad$ Conjunction & 3.2 & 2.9 & 2.3 \\
Standard top-up preview & 3.3 & 2.1 & 1.5 \\
Top-up preview in the blink & 0.9 & 0.6 & 0.0 \\
Top-up preview not in the blink & 3.1 & 0.9 & 0.4 \\
Experiment 2 & & & \\
Conjunction & 2.1 & 1.1 & 0.4 \\
450 ms initial preview in the blink & 3.7 & 2.4 & 0.7 \\
450 ms initial preview with no blink & 2.9 & 1.4 & 0.5 \\
\hline
\end{tabular}


TABLE 3

Descriptive statistics for Experiment 1

\begin{tabular}{ccccc}
\hline & Conjunction & $\begin{array}{c}\text { Standard top-up } \\
\text { preview }\end{array}$ & $\begin{array}{c}\text { Top-up preview } \\
\text { in the blink }\end{array}$ & $\begin{array}{c}\text { Top-up preview } \\
\text { outside the blink }\end{array}$ \\
\hline Slope (ms/item) & 42.0 & 31.7 & 39.9 & 29.6 \\
\hline
\end{tabular}

Conjunction vs. the top-up preview inside the blink. There was a reliable main effect of display size, $F(2,20)=75.61, p<.01$, however there was no main effect of condition, $F(1,10)=0.53, p=n s$. The Condition $\times$ Display size interaction was also not significant, $F(2,20)=0.46, p=n s$.

Conjunction vs. the top-up preview outside the blink. There was a reliable main effect of display size, $F(2,20)=55.04, p<.01$. There was no main effect of condition, $F(1,10)=0.23, p=n s$, but the Condition $\times$ Display size interaction did reach significance, $F(2,20)=5.38, p<.05$. There was a greater increase in RTs with display size in the conjunction condition than in the top-up preview.

Standard top-up preview vs. the top-up inside the blink. There was a reliable main effect of condition, $F(1,10)=5.10, p<.05$ and of display size, $F(2,20)=69.40, p<.01$. The Condition $\times$ Display size interaction also reached significance, $F(2,20)=6.81, p<.01$. There was a greater increase in RTs with display size when the preview appeared during the attentional blink period compared to the standard top-up preview.

Standard top-up preview vs. the top-up outside the blink. There was a reliable main effect of condition, $F(1,10)=5.310, p<.05$ and of display size, $F(2,20)=48.62, p<.01$. However, the Condition $\times$ Display size interaction was not reliable, $F(2,20)=0.37, p=n s$.

Top-up in the blink preview vs. the top-up preview outside the blink. There was a reliable main effect of display size, $F(2,20)=74.73, p<.01$. There was no main effect of condition, $F(1,10)=0.24, p=n s$, but the Condition $\times$ Display size interaction did reach significance, $F(2,20)=5.73, p<.05$. There was a greater increase in RTs with display size in the preview condition with the top-up inside the blink compared to when the top-up appeared outside the blink.

\section{Errors}

There was a main effect of condition, $F(3,30)=4.06, p<.05$, where error rates were greatest in the conjunction condition and smallest in the top-up 
preview inside the blink condition, and also a main effect of display size, $F(2$, $20)=4.73, p<.05$, where error rates decreased over display size. ${ }^{1}$ However, the Condition $\times$ Display size interaction was not reliable, $F(6,60)=0.54$, $p=n s$.

\section{Discussion}

Performance in the top-up condition replicated the data from Kunar et al. (2003): Search was more efficient in the top-up preview compared to the conjunction baseline. This is despite the fact that the short top-up alone has been shown to induce a minimal preview effect (Humphreys et al., 2004; Kunar et al., 2003), whilst the preview benefit is eliminated by offsetting the preview and then re-presenting it along with the search items (Kunar, Humphreys, Smith, \& Watson, 2003; Watson \& Humphreys, 1997). It is the combined presence of the first preview plus the top-up that induces a preview benefit. This preview benefit on search slopes was maintained when participants performed a secondary task (when the preview was combined with the $\mathrm{AB}$ procedure), but only when the top-up appeared outside the AB. In contrast when the top-up fell inside the blink period there was a cost to search efficiency. This occurred even though observers, in this condition, had more time to code the preview compared with when the topup fell outside the $\mathrm{AB}$ (600 ms before T1 vs. $450 \mathrm{~ms}$ before $\mathrm{T} 1)$. It does seem critical then, that attention must be maintained following any initial coding of the preview in order for these old items to be subsequently ignored in search.

Importantly, this result runs counter to the argument that the preview benefit is caused by automatic attention capture by the new items (Donk \& Theeuwes, 2001) or automatic temporal segmentation (Jiang et al., 2002). On both of these views, the $\mathrm{AB}$ during the top-up period should have minimal impact on performance. The results are also problematic for a revised version of the onset capture account. This version holds that, under top-up conditions, IOR is applied to the initial preview, which then reduces attention to the re-presented old items As a result, the old items are ignored and a preview benefit emerges as the new items capture attention (Donk \& Verburg, 2004). On this account, presenting the top-up during an AB should, if anything, enhance the preview benefit, since it would mean that the top-up display is even more likely to be ignored relative to when it is

\footnotetext{
${ }^{1}$ We recognize that the pattern of error rates, over display size in both Experiment 1 and Experiment 2, may appear counterintuitive (i.e., we might expect that, if anything, errors should increase over display size) but as the change in error rate was small $(1.6 \%$ and $2.4 \%$ in Experiments 1 and 2, respectively) we do not wish to put too much emphasis on this effect.
} 
attended. We found the opposite. The data clearly indicate that resources must be devoted to the top-up display, to prevent these items entering into search.

When the top-up display appeared outside the $\mathrm{AB}$, there was little effect on search slopes. This demonstrates that the mere appearance of the T1 letter and the mask was not sufficient to disrupt search performance. There was, however, an intercept effect on search; RTs were overall slowed when the secondary task was present compared to the standard preview condition. This may reflect some general cost from scheduling two tasks together, and/ or holding a memory load for the T1 letter. The more crucial point is that any general scheduling effect did not disrupt search. Instead it seemed that the availability of attention, in the top-up period, determined search efficiency.

Although we have pointed out difficulties for both the onset capture and temporal segmentation accounts, it is possible to reformulate these proposals to explain the data, if it is assumed that either temporal grouping or onset capture are influenced by attention. It may be that attention to the top-up is needed to enable the new and old stimuli to be assigned to separate temporal groups. Without attention, the binding of items into old and new groups may not take place with the result that all items are grouped as one. Similarly, if attention is withdrawn prior to the onset of the new items then their onset may not be as salient as when attention is present (Donk \& Theeuwes, 2003). Here a preview effect would fail to emerge, as spatial attention may be engaged on consolidating a representation of $\mathrm{T} 1$ for report, reducing attentional capture by the new stimuli.

The temporal grouping and onset capture accounts both suppose that attentional resources are weighted towards the end of the preview period, to optimize search. Attention needs to be available immediately prior to the onset of the new items to either (a) segregate the old from the new or (b) allow the onset of the new items to be fully salient. Thus, removing attention from the beginning of the preview period should not disrupt search. In contrast removing attention from the beginning of the preview effect may disrupt search if a representation of the old items needs to be encoded and suppressed (cf. Watson \& Humphreys, 1997). Humphreys et al. (2002) found that removing attention from the onset of the previewed items disrupted the preview effect. To test this hypothesis we reduced the amount of attention available during preview search by generating an attentional blink prior to the onset of the previewed items. If attention is important in this phase then the magnitude of the preview effect should be reduced in comparison to the condition when attention is fully available. 


\section{EXPERIMENT 2}

In Experiment 2, we compare a top-up preview search where the initial onset of the previewed items was presented within an attentional blink to a condition where no attentional blink was produced. In the latter condition attentional resources should be fully available, whereas, in the former, attentional resources should be reduced. All conditions in Experiment 2 also required participants to report the identity of a white letter presented before the search displays. In this way each condition should be equated for working memory load throughout the trial. As we noted in the Discussion of Experiment 1, there was an intercept in the top-up outside the blink condition, whereby the intercept of the search function was raised when the blink appeared mid-way through the initial preview period. This could reflect a general cost from performing the letter report and search tasks together, or could reflect the memory load of the T1 target. In either case, the same would now hold across conditions.

\section{Method}

Participants. Twelve participants ( 2 male and 10 female) took part for the attainment of course credits. Their ages ranged from 18 to 52 (mean age 24.9 years) and they were all taken from a population of undergraduates at the University of Wales, Bangor. All participants had normal or correctedto-normal eyesight.

Stimuli. The stimuli were identical to those used in Experiment 1.

Design and procedure. Each participant was tested in three conditions: (a) A conjunction baseline; (b) a top-up preview condition with a $450 \mathrm{~ms}$ initial preview; and (c) a top-up preview condition, where the initial preview now appeared during an $\mathrm{AB}$ (the top-up preview $\mathrm{AB}$ condition). Each search condition was presented in a separate block. The experimental blocks each contained 90 trials ( 30 per display size). The order of the blocks was randomized and participants were given a practice session before each condition. The experiment lasted approximately $40 \mathrm{~min}$ in total.

The conjunction baseline condition differed slightly from that in Experiment 1. Here, $598 \mathrm{~ms}$ prior to the search set appearing (green $\mathrm{Hs}$, blue As, and a blue $\mathrm{H}$ target), participants were presented with $\mathrm{T} 1$ for $24 \mathrm{~ms}$ and its mask, which appeared after an ISI of $41 \mathrm{~ms}$, for $74 \mathrm{~ms}$. After responding to the position of the bar on the blue $\mathrm{H}$, participants were asked to identify the white letter. In this case, the search display should not be affected by the generated attentional blink but if there was a detrimental 
affect of holding $\mathrm{T} 1$ in memory then this would be equal and comparable for all search conditions. ${ }^{2}$

In the top-up preview $\mathrm{AB}$ condition, $\mathrm{T} 1$ was presented for $24 \mathrm{~ms}$ followed after an ISI of $41 \mathrm{~ms}$ by its mask, which was presented for $74 \mathrm{~ms}$. Immediately after the offset of the mask, green Hs were presented for 450 $\mathrm{ms}$, before they offset for $250 \mathrm{~ms}$ and reappeared for $150 \mathrm{~ms}$ prior to the onset of the blue items. Participants were instructed to first respond to the bar of the blue $\mathrm{H}$ as quickly but as accurately as they can and then to respond to the identity of the white letter. The $450 \mathrm{~ms}$ top-up with no attentional blink condition was the same, except that in this case T1 was not followed by a mask. ${ }^{3}$ Previous work has shown that if T1 is unmasked no AB ensues (e.g., Raymond et al., 1992). In this case, participants would still have to retain $\mathrm{T} 1$ in memory throughout the initial preview period but attention should be fully available. Example displays can be seen in Figure 3. In this study, the initial preview was reduced to $450 \mathrm{~ms}$ in order to ensure that it fell within the $\mathrm{AB}$, with little "recovery time" left after the blink to subsequently encode the preview.

\section{Results}

Participants correctly reported $\mathrm{T} 1$ on $92 \%$ of the trials. Table 1 shows the percentage of $\mathrm{T} 1$ errors for each condition across display size. There was no effect of T1 accuracy on condition, $F(2,22=0.4, p=n s$, display size, $F(2$, $22)=1.9, p=n s$, nor a reliable Condition $\times$ Display size interaction, $F(4$, 44) $=0.7, p=n s$. Trials where T1 was not correctly identified were discarded from further analysis. Figure 4 shows the mean correct RTs as a function of display size. The error rates are given in Table 2 and Table 4 shows the descriptive statistics.

\section{$R T s$}

A two-way within-subjects analysis of variance (ANOVA), with condition and display size as its main factors, was used to compare the RTs for all

\footnotetext{
${ }^{2}$ It is important to note that a baseline experiment found that there was no difference, in terms of search slopes, between this conjunction condition (preceded by a target and its mask) and the conjunction condition found in Experiment 1 (where $\mathrm{T} 1$ and its mask were not presented), $F(2,24)=1.54, p=n s$.

${ }^{3}$ Please note that this preview baseline differs from that in Experiment 1, where an $\mathrm{AB}$ was generated but the top-up preview fell outside the blink. This change in baseline, however, should not affect the results. Pilot work showed there to be little difference, in terms of search slope, when $\mathrm{T} 1$ was not masked compared to a condition where an attentional blink was generated but then dissipated before the onset of the initial preview, $F(2,20)=1.9, p=n s$. This was not surprising considering that in both tasks attention was available for the initial preview.
} 
Conjunction

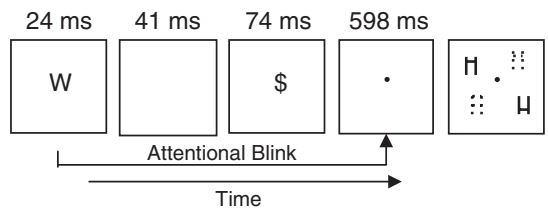

Top-up preview $A B$

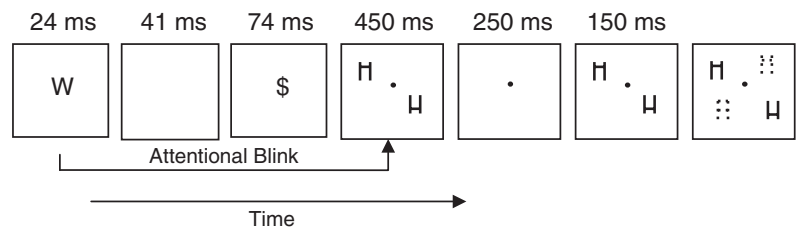

Preview-no blink

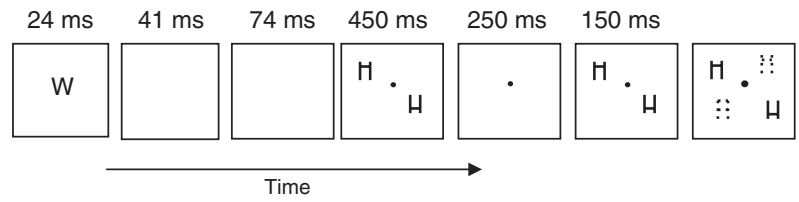

Figure 3. Example displays of each condition in Experiment 2. Solid lines represent green items, whereas dotted lines represent blue stimuli. Due to figure size constraints we only present four items in each display. In the experiment proper the displays contain 4, 8, or 16 items, which appear at random locations within the display. Please note that the scale of each item is not to size.

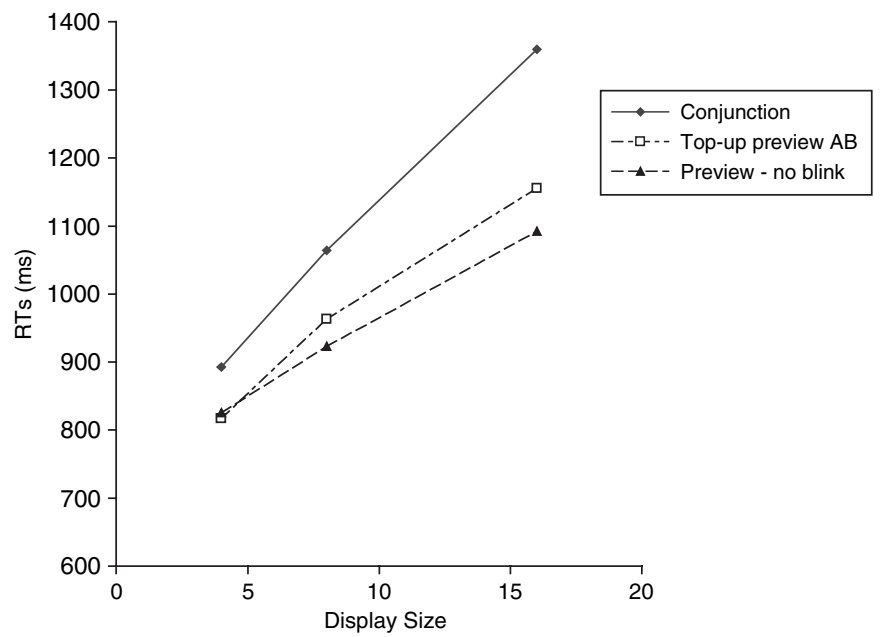

Figure 4. Mean correct RTs (ms) for each condition in Experiment 2. 
TABLE 4

Descriptive statistics for Experiment 2

\begin{tabular}{lccc}
\hline & Conjunction & $\begin{array}{c}450 \text { ms initial preview } \\
\text { in the blink }\end{array}$ & $\begin{array}{c}450 \text { ms initial preview } \\
\text { with no blink }\end{array}$ \\
\hline Slope (ms/item) & 38.6 & 27.6 & 22.1 \\
\hline
\end{tabular}

conditions. There was a reliable main effect of condition, $F(2,22)=8.72$, $p<.01$ and of display size, $F(2,22)=78.71, p<.01$. The Condition $\times$ Display size interaction also reached significance, $F(4,44)=9.36, p<.01$. The ANOVA was then broken down so that individual comparisons between conditions could be made.

Conjunction vs. the top-up preview AB condition. There was a reliable main effect of condition, $F(1,11)=14.12, p<.01$, and of display size, $F(2$, $22)=79.53, p<.01$. The Condition $\times$ Display size interaction also reached significance, $F(2,22)=6.71, p<.01$. There was a greater increase in RTs with display size in the conjunction condition than in the top-up preview $\mathrm{AB}$ condition.

Conjunction vs. the preview-no blink condition. There was a reliable main effect of condition, $F(1,11)=12.02, p<.01$ and of display size, $F(2,22)=$ $70.82, p<.01$. The Condition $\times$ Display size interaction also reached significance, $F(2,22)=13.01, p<.01$. There was a greater increase in RTs with display size in the conjunction condition than in the $450 \mathrm{~ms}$ top-up with no attentional blink condition.

Top-up preview $A B$ condition vs. the preview-no blink condition. There was a reliable main effect of display size, $F(2,22)=61.35, p<.01$, but not of condition, $F(1,11)=0.63, p=n s$. However the Condition $\times$ Display size interaction did reach significance, $F(2,22)=5.27, p<.05$. Search was more efficient in the preview no-blink condition than when the top-up preview appeared during the attentional blink.

\section{Errors}

There was a small but reliable main effect of display size (where errors decreased with increasing display size), $F(2,22)=3.71, p<.05$, but not of condition, $F(2,22)=2.70, p=n s$. Neither was the Condition $\times$ Display size interaction reliable, $F(4,44)=0.43, p=n s$. 


\section{Discussion}

The results were clear. In the condition with a top-up preview and no blink, there was an overall benefit for preview search relative to the conjunction baseline. This again confirms the robust nature of the basic top-up effect in search (cf. Kunar et al., 2003). Here a benefit was established with a preview of $450 \mathrm{~ms}$. In the results of Humphreys et al. (2004) a duration of $450 \mathrm{~ms}$ produced close to asymptotic performance in preview search (see also Watson \& Humphreys, 1997). In the top-up preview condition with a blink there was again a moderate preview benefit compared with the conjunction condition, but search efficiency nevertheless suffered relative to when there was no $\mathrm{AB}$ (i.e., in the blink condition, the slopes fell halfway between the preview-no blink and the conjunction baseline). This is consistent with there being an effect of reducing resources during the early part of the top-up procedure, presumably when the initial preview is encoded. Moreover, these data corroborate the argument made by Humphreys et al. (2002) that attention may be needed both when previews are initially presented, and at the end period of their presentation, in order to prevent the previews from affecting search. Here, Experiment 1 found that attention was needed at the latter part of the preview in order to produce more efficient search, whereas Experiment 2 showed that attention is also important in the earlier stage of the preview period.

Although there was evidence of an $A B$ effect on preview search, it is also important and interesting to note that, overall, withdrawing attention at the early stage of stimulus presentation did not return performance to baseline. There may be several reasons for this. Firstly, perhaps the task used here did not consume enough attention. On first glance this seems unlikely, given that the preview effect was removed in Experiment 1 using the same stimuli but with different timings (indeed, the initial preview was shorter here). However, this theory may be plausible, if we select the premise that the effectiveness of the $A B$ is modulated by the set size and onsets of the preview display. Here if the luminance onset of this initial preview display was large enough its signal might override the $\mathrm{AB}$, in part, allowing the previewed items to be attended. This notion is expanded upon in the General Discussion. Another explanation would be that attention was not removed for the entire initial preview period. Our pilot study found that using these stimuli, the attentional blink began its recovery $355 \mathrm{~ms}$ after $\mathrm{T} 1$ had been shown. ${ }^{4}$ Comparing these timings to that of the initial preview period we see that attention would therefore be available for approximately $200-250 \mathrm{~ms}$ of

\footnotetext{
${ }^{4}$ The attentional blink is said to recover when T2 accuracy reaches the level of a single target baseline. Here participants are asked to ignore T1 and only report the identity of T2. At this point $\mathrm{T} 1$ 's attentional demands no longer affect $\mathrm{T} 2$, i.e., attention is fully available to process $\mathrm{T} 2$.
} 
the latter part of the initial preview effect. It may therefore be possible that some of the preview display had been attended, and this led to a partial preview effect. This preview benefit, although present, would be smaller than a preview benefit that was obtained when attention was fully available.

Note that in Experiment 1, the blink may also have begun its recovery during the top-up period, and so like the initial period in Experiment 2, it may not have been wholly encompassed in the blink. However, in Experiment 1 the top-up preview in the blink showed no difference, in terms of search slopes, from the conjunction condition (unlike that of Experiment 2). There are two possible reasons for this. Firstly, when the blink dissipated in Experiment 1, there was less time (if any) available for attention to process the top-up than when the blink dissipated in Experiment 2. In this case, we would expect to find a smaller preview benefit in Experiment 1, relative to a conjunction. Secondly, perhaps the maintenance process may be more vulnerable to disruption than the initial encoding process. Although possible we do not believe this to be the case. Humphreys et al. (2002) found that the initial encoding procedure could be disrupted by both visual and auditory stimuli, whereas the maintenance process was only disrupted by visual stimuli. This suggests that, if anything, the initial encoding process is more vulnerable to decay. We note, though, that Humphreys et al. kept the initial display present throughout the preview period, whereas we removed the preview; thus the demands on maintenance of the preview may have been higher here.

The finding that the initial preview period is important contradicts the proposals made by the temporal grouping and onset capture accounts. Most notably both the $\mathrm{AB}$ and the initial preview occurred here long before the search display, leaving a good deal of time either to segment the preview from the search display or to allocate attention to the new display (to optimize onset capture). Despite this, the preview effect suffered following the early AB. We discuss accounts that remain consistent with the data in the General Discussion.

\section{GENERAL DISCUSSION}

Two experiments investigated the need for attention in top-up preview search. Experiment 1 found that attention is needed for the latter part of the top-up procedure in order to produce efficient search. If attention is withdrawn from this period, search resembles that of a conjunction task. Experiment 2 found that attentional processes are also needed in the initial preview period. Withdrawing attention here reduced the preview benefit. 


\section{Implications for preview mechanisms}

The data from the present set of experiments provide us with insights into the mechanisms responsible for preview search. Furthermore, they are problematic for particular accounts of the role of the preview in visual search. As mentioned previously there are three main accounts for the preview benefit: (a) Inhibitory filtering of old distractors (Watson \& Humphreys, 1997), (b) temporal grouping and segmentation of old and new displays (Jiang et al., 2002), and (c) attentional capture by new onsets (Donk \& Theeuwes, 2001). The data from Experiment 1 counter strong versions of the temporal segmentation and attentional capture accounts that assume that processing is fully automatic; the results clearly show that attention needs to be applied to the top-up items in order to keep them out of the subsequent search process. The results also are not able to be reconciled with the adaptation of the onset capture account put forward by Donk and Verburg (2004) to explain why a preview benefit arises under topup conditions. Donk and Verburg proposed that IOR might be applied to the initial old items, which then stops them from capturing attention when they are re-presented as the top-up. This in turn allows the new items to capture attention. On this view, though, presenting the top-up during an AB should not disrupt performance, since the top-up items are thought to be unattended in the first place (indeed, if anything, it would be expected to improve search, as the old items would be even less likely to capture attention). The data, however, showed the opposite effect. In contrast to the onset capture view, the effects of the $\mathrm{AB}$ on the top-up display can be accounted for if the blink (a) prevents the previewed items from being reencoded and thus reduces any inhibitory filtering (Watson \& Humphreys, 1997), or (b) prevents the top-up items from forming a separate temporal group from the new stimuli (Jiang et al., 2002).

The conclusions from the results of Experiment 1 (i.e., AB occurring during the latter top-up) are complemented by the data from Experiment 2, when the $\mathrm{AB}$ was allowed to exert its effect early during the preview. These data are more difficult to explain in terms of any simplistic view of temporal segmentation, which holds that the long time period between the initial preview and the subsequent top-up and search displays should be enough to form separate temporal groups (see Yantis \& Gibson, 1994, for evidence of temporal segmentation with separations of $100 \mathrm{~ms}$ ). The results can be explained, however, in terms of inhibitory visual marking. This account specifically addresses the need for the preview items to be encoded and attended during the initial preview period. Watson and Humphreys (1997) found that the old items need to be presented for around $400-500 \mathrm{~ms}$ in order to produce efficient search (see also Humphreys et al., 2004). If they are presented for less time, the preview effect in search is reduced. 
Humphreys et al. proposed that there needs to be time to encode the old items initially, to subsequently mark them as irrelevant. Following on from this, the present results are important in revealing that attentional resources need to be available for this initial period so that the old items can be encoded before being filtered. If attention is withdrawn then presumably there are insufficient resources to efficiently mark the old items and hence the preview effect suffers.

\section{Display size, onsets, and the effectiveness of the $A B$}

On the whole, the data suggest that the initial preview and the latter top-up preview both require attention in order for a preview effect to occur. Withdrawing attention before either of these stages seems to disrupt the overall preview effect. Is this pattern consistent over display size or are there differential effects depending on the number of items to be discounted from search? Our data suggest that display size may indeed play a role. First, let us examine data from Experiment 2. Figure 4 suggests that from display size 4 to 8 , the slope of the initial preview in the blink condition is steeper than the top-up preview with no blink condition. However, from display size 8 to 16, the difference between these two slopes is minimal. This difference was confirmed statistically. ${ }^{5}$ In Experiment 2, it seems that the attentional blink is disrupting search more when the set size is small than when it is large when the preview items first appear.

Why should this be? We suggest that this may occur as the effectiveness of the $\mathrm{AB}$ to disrupt search is dependent on the size of the display. If the display size is small then the previewed items can be completely accommodated into the $\mathrm{AB}$ so that preview search is disrupted. However, if the display size is large then the onsets in the preview may themselves interrupt or reduce the $\mathrm{AB}$, making it less effective. In the latter case, items from the preview may be coded and discounted from later search, at least to some degree. Interestingly, there was complete loss of the preview effect for the larger display sizes in Experiment 1 when the top-up display appeared within the AB (i.e., search slopes were different to both the other top-up preview conditions, but not to the conjunction condition). On first glance, it may appear counterintuitive that the same AB can "knock-out" large set sizes when they are presented as a top-up, but not when they are presented initially. However, if we remember that the top-up preview is a returning display that has been viewed and, presumably, inhibited previously, the data can be accounted for. For

\footnotetext{
${ }^{5}$ Search slopes were steeper in the initial preview in the blink than in the top-up preview with no blink between display sizes $4-8, F(1,11)=12.4, p<.01$, but not between set sizes $8-16$, $F(1,11)=0.9, p=n s$.
} 
example, when a display containing a large set size first appears it may capture attention thereby reducing the effectiveness of the blink. On the other hand, if the same display is viewed a second time, its onset may be rendered as less salient. Here a previously seen display will have less impact on the $\mathrm{AB}$ so that it, in turn, would be able to be successfully blinked (thus, eliminating the preview benefit).

\section{Further support for a two-stage marking mechanism}

The data support the notion that there may be two stages in the preview effect (Humphreys et al., 2002): Each of which require attention. In the first stage, attention is needed to encode the initial display and mark it as irrelevant. The second stage involves the consolidation of the representation of the old items. Both of these stages are important in the usual preview effect (Humphreys et al., 2002), but the second stage is especially important in top-up search. Without this secondary process the previewed items cannot be matched to the initial preview and, we suggest, are not subject to continued inhibition. The nature of the representations mediating this effect has yet to be specified. For example, as well as there being evidence for inhibition at the locations of old items (e.g., Watson \& Humphreys, 2000), other results suggest that there can be suppression of the colours and orientations of previews too (Braithwaite, Humphreys, \& Hodsoll, 2003; Olivers \& Humphreys, 2003). Furthermore, recent work in our laboratory has suggested that filtering on the basis of object representations can also occur (i.e., even when the locations of the old items change between the initial and the top-up preview displays). ${ }^{6}$ Stimuli can still be discounted from search even if they are not separated from new stimuli on the basis of colour or location (Kunar \& Humphreys, in press).

\section{Amalgamating temporal grouping with visual marking}

As mentioned above, a simplistic version of temporal grouping cannot account for the present data. However, a revised version can. For this account we add the constraint that the formation of old and new groups is not an automatic process but requires time and attention. If resources are not readily available during the initial preview period then the grouping of the old distractors may not be absolute and so cannot be "topped up" when the items reappear. For this account to hold, we must suppose that the 150

\footnotetext{
${ }^{6}$ Note that this result is also difficult for the idea that IOR, applied to the locations of the old stimuli, leads to the top-up items being ignored when the new items are presented (Donk \& Verburg, 2004).
} 
ms top-up of the preview alone is not long enough to allow the complete grouping of the old items and their segmentation from the new displays. Hence, with this top-up display alone, the preview items continue to compete with the new items disrupting search. The presence of an earlier preview, however (prior to the $150 \mathrm{~ms}$ top-up display), may facilitate the grouping of the old items and their subsequent segmentation from the new set. This integration of the initial preview and the top-up also appears to demand attention, and so is disrupted when an attentional blink is introduced both early and late in the preview period. This revised temporal grouping and segmentation account is very similar to the original visual marking account (see Watson, Humphreys, \& Olivers, 2003). On each proposal, the grouping and segmentation of preview and new displays is relatively slow and requires attention. The main difference is whether inhibition is applied to the old items. The main evidence for such inhibition comes from studies of probe detection, where it has been shown that probes are difficult to detect when they occur at the locations of old items (Braithwaite, Humphreys, \& Hulleman, 2005; Olivers \& Humphreys, 2002; Watson \& Humphreys, 2000). We maintain, therefore, that even if temporal grouping and segmentation is important (and see Kunar et al., 2003, for converging evidence from the top-up procedure), this process is modulated by inhibition of old items. Both mechanisms may operate to generate efficient search of the new set under preview conditions. We suggest that future studies should work on the amalgamation of current accounts of the preview effect into a unified whole.

\section{REFERENCES}

Braithwaite, J. J., Humphreys, G. W., \& Hodsoll, J. (2003). Color grouping in space and time: Evidence from negative color-based carry-over effects in preview search. Journal of Experimental Psychology: Human Perception and Performance, 29, 758-778.

Braithwaite, J. J., Humphreys, G. W., \& Hulleman, J. (2005). Color-based grouping and inhibition in visual search: Evidence from a probe-detection analysis of preview search. Perception and Psychophysics, 67, 81-101.

Donk, M., \& Theeuwes, J. (2001). Visual marking beside the mark: Prioritizing selection by abrupt onsets. Perception and Psychophysics, 63, 891-900.

Donk, M., \& Theeuwes, J. (2003). Prioritizing selection of new elements: Bottom-up versus topdown control. Perception and Psychophysics, 65, 1231-1242.

Donk, M., \& Verburg, R. (2004). Prioritizing new elements with a brief preview period: Evidence against visual marking. Psychonomic Bulletin and Review, 11, 282-288.

Humphreys, G. W., Kyllingsbaek, S., Watson, D. G., Olivers, C. N. L., Law, I., \& Paulson, O. (2004). Parieto-occipital areas involved in efficient filtering in search: A time course analysis of visual marking using behavioural and functional imaging procedures. Quarterly Journal of Experimental Psychology, 57A, 610-635. 
Humphreys, G. W., Watson, D. G., \& Jolicoeur, P. (2002). Fractionating visual marking: Dualtask decomposition of the marking state by timing and modality. Journal of Experimental Psychology: Human Perception and Performance, 28, 640-660.

Jiang, Y., Chun, M. M., \& Marks, L. E. (2002). Visual marking: Selective attention to asynchronous temporal groups. Journal of Experimental Psychology: Human Perception and Performance, 28, 717-750.

Jiang, Y., \& Wang, S. W. (2004). What kind of memory supports visual marking? Journal of Experimental Psychology: Human Perception and Performance, 30, 79-91.

Kunar, M. A., \& Humphreys, G. W. (in press). Object-based inhibitory priming in preview search: Evidence from the "top-up" procedure. Memory and Cognition .

Kunar, M. A., Humphreys, G. W., \& Smith, K. J. (2003). History matters: The preview benefit in search is not onset capture. Psychological Science, 14, 181-185.

Kunar, M. A., Humphreys, G. W., Smith, K. J., \& Watson, D. G. (2003). When a re-appearance is old news: Visual marking survives occlusion. Journal of Experimental Psychology: Human Perception and Performance, 29, 185-198.

Olivers, C. N. L., \& Humphreys, G. W. (2002). Visual marking under attentional blink conditions: More evidence for top-down limited capacity inhibition. Journal of Experimental Psychology: Human Perception and Performance, 28, 22-42.

Olivers, C. N. L., \& Humphreys, G. W. (2003). Visual marking and singleton capture: Fractionating the unitary nature of visual selection. Cognitive Psychology, 47, 1-42.

Raymond, J. E., Shapiro, K. L., \& Arnell, K. M. (1992). Temporary suppression of visual processing in an RSVP task: An attentional blink? Journal of Experimental Psychology: Human Perception and Performance, 18, 849-860.

Shapiro, K. L., Arnell, K. A., \& Raymond, J. E. (1997). The attentional blink: A view on attention and a glimpse on consciousness. Trends in Cognitive Science, 1, 291-296.

Ward, R., Duncan, J., \& Shapiro, K. (1997). Effects of similarity, difficulty, and nontarget presentation on the time course of visual attention. Perception and Psychophysics, 59, 593600.

Watson, D. G., \& Humphreys, G. W. (1997). Visual marking: Prioritizing selection for new objects by top-down attentional inhibition of old objects. Psychological Review, 104, 90122.

Watson, D. G., \& Humphreys, G. W. (2000). Visual marking: Evidence for inhibition using a probe-dot detection paradigm. Perception and Psychophysics, 62, 471-481.

Watson, D. G., Humphreys, G. W., \& Olivers, C. N. L. (2003). Visual marking: Using time in visual selection. Trends in Cognitive Sciences, 4, 180-186.

Yantis, S., \& Gibson, B. S. (1994). Object continuity in apparent motion and attention. Canadian Journal of Experimental Psychology, 48, 182-204.

Manuscript received March 2005 Manuscript accepted November 2005 